\title{
Bernard Maris, Houellebecq économiste
}

\section{Aron Verga}

\section{OpenEdition}

\section{Journals}

\section{Edizione digitale}

URL: http://journals.openedition.org/studifrancesi/1477

DOI: 10.4000/studifrancesi. 1477

ISSN: 2427-5856

\section{Editore}

Rosenberg \& Sellier

\section{Edizione cartacea}

Data di pubblicazione: 1 décembre 2015

Paginazione: 634-635

ISSN: 0039-2944

\section{Notizia bibliografica digitale}

Aron Verga, «Bernard Maris, Houellebecq économiste», Studi Francesi [Online], 177 (LIX | III) | 2015,

online dal 01 décembre 2015, consultato il 06 janvier 2021. URL: http://journals.openedition.org/ studifrancesi/1477; DOI: https://doi.org/10.4000/studifrancesi. 1477

\section{Questo documento è stato generato automaticamente il 6 janvier 2021.}

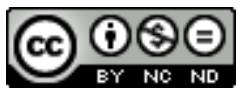

Studi Francesi è distribuita con Licenza Creative Commons Attribuzione - Non commerciale - Non opere derivate 4.0 Internazionale. 


\title{
Bernard Maris, Houellebecq économiste
}

\author{
Aron Verga
}

\section{NOTIZIA}

BERNARD MARIS, Houellebecq économiste, Paris, Flammarion, 2014, pp. 155.

1 Questo saggio rischia di essere ricordato perché l'autore, Bernard Maris, economista, giornalista, scrittore, fu una delle vittime dell'attentato alla rivista satirica «Charlie Hebdo». È bene dunque rammentare che si tratta di un pamphlet contro la maniera di vivere di un Occidente succube delle politiche dettate dall'astrazione e dalle cifre dell'economia. Sin dalle prime pagine è chiaro il bersaglio di Bernard Maris: «L'économiste est celui qui est toujours capable d'expliquer ex post pourquoi il s'est, une fois de plus, trompé» (p. 14). È un libro suddiviso in cinque capitoli preceduti da un prologo e chiusi da un capitolo mascherato da epilogo. Ogni parte descrive un tema economico e le relative teorie di grandissimi economisti: «Le règne absolu des individus ou Alfred Marshall»; «L'entreprise et la destruction créatrice ou Joseph Schumpeter»; «L'infantilisme des consommateurs ou John Maynard Keynes»; «L'utile et l'inutile ou Marx et Fourier»; «Au bout du capitalisme ou Thomas Robert Malthus»; «Qui mérite la vie éternelle? Ou (de nouveau) John Maynard Keynes». L'autore sottolinea a più riprese che l'economia non è una scienza, anzi, non è nulla, sostiene persino che tra un secolo circa ci si stupirà di come una civiltà abbia potuto concedere tanta importanza «à une discipline non seulement vide mais terriblement ennuyeuse» (p. 14).

2 Per dare più forza al proprio pensiero, Bernard Maris si affida ai romanzi di Michel Houellebecq. Quest'ultimo, nelle sue opere, affronta il tema del denaro, del lavoro parassitario e di quello utile, della produttività, della competizione, della distruzione creatrice. In Extension du domaine de la lutte la narrazione ruota attorno all'argomento del liberalismo e della competizione, nelle Particules élémentaires si parla di consumismo e di individualismo assoluto, Plateforme affronta la questione della domanda e 
dell'offerta in ambito sessuale, La Possibilité d'une île racconta di una società postcapitalista che ha realizzato il sogno dei consumatori, la vita eterna. Infine, La Carte et le territoire esamina il lavoro, l'arte e la distruzione creatrice. Tutti temi economici, che trattati dagli esperti della materia risulterebbero di difficile comprensione per i non iniziati; mentre Houellebecq, in quanto scrittore, li presenta meglio, mettendo in evidenza in particolare la guerra umana per preservare la propria solitudine egoista.

È la battaglia voluta dal liberalismo economico, una lotta di tutti contro tutti ben descritta nel primo romanzo di Michel Houellebecq, Extension du domaine de la lutte, «qui ne pourrait plus être publié aujourd'hui. Parce que nos sociétés en sont maintenant arrivées à ce stade terminal où elles refusent de reconnaître leur mal-être» (p. 143). Bernard Maris sottolinea come Houellebecq illustri da una parte un mondo, quello degli economisti, dove esistono solo egoismo, crudeltà e cinismo, dall'altra un punto di vista opposto, dove al primo posto vi sono la bontà e l'amore, parole che nell'epoca economica contemporanea sono inconcepibili, astratte. Invece per lo scrittore l'amore è il vero desiderio, ma le litanie ripetute a oltranza dalla società di mercato hanno infantilizzato il desiderio dei consumatori, destinato a restare sempre inesaudito. Pertanto alla fine per Houellebecq sopravvivranno solo i sognatori, i poeti, le donne, poiché più altruiste dei loro compagni, e chi non si sottomette agli stimoli del denaro. In altre parole, quello che Maris definisce «anti-homo-œconomicus» (p. 67). In conclusione Maris riprende la domanda del romanzo La Possibilité d'une île, «Qui mérite la vie éternelle?», che per Houellebecq ha una sola risposta: coloro che sono capaci di bontà. Ancora una volta un saggio che ci presenta l'opera di Michel Houellebecq sotto una luce differente da quella normalmente evidenziata dai media, limitata il più delle volte al suo lato pruriginoso. 